\section{Prevalence of atherosclerosis risk factors in Egyptian patients with acute coronary syndrome: final data of the nationwide cross-sectional 'CardioRisk' project}

\begin{abstract}
Ashraf Reda, ${ }^{1}$ Ahmed Bendary, ${ }^{2}$ Atef Elbahry, ${ }^{3}$ Elsayed Farag, ${ }^{4}$ Tamer Mostafa, ${ }^{4}$ Hazem Khamis, ${ }^{5}$ Moheb Wadie, ${ }^{6}$ Mohamed Bendary, Bassant Abdoul Azeem, ${ }^{8}$ Rehab Salah, ${ }^{9}$ for the CardioRisk investigators*

${ }^{1}$ Cardiology Department, Faculty of Medicine, Menofia University; Streptokinase) was used in $24 \%$ of included participants.

Conclusion: Among Egyptian patients with ACS, premature presentation is common with greater male preponderance. Abdominal obesity is the most prevalent risk factor followed by hypertension. Most traditional risk factors (apart from smoking) were more prevalent in women than men.
\end{abstract}

${ }^{2}$ Cardiology Department, Faculty of Medicine, Benha University; ${ }^{3}$ Cardiology Unit, Port Fouad Centre, Port Fouad; ${ }^{4}$ Cardiology Department, Faculty of Medicine, Zagazig University; ${ }^{5}$ Cardiology Department, Faculty of Medicine, October University;

${ }^{6}$ Cardiology Department, Faculty of Medicine, Mansoura University; ${ }^{7}$ Biostatistics Department, National Cancer Institute, Cairo University; ${ }^{8}$ Critical Care Department, Faculty of Medicine, Cairo University; ${ }^{9}$ Faculty of Medicine, Benha University, Egypt

*A complete list of contributors is available as ad hoc appendix

\section{Abstract \\ Background: Little are known about the prevalence of atherosclerosis risk factors in Egyptian patients with acute coronary syn- dromes (ACS). \\ Objective: Describe the prevalence of these risk factors with focus on gender-spe- cific data and patients with premature pres-} entation.

Methods: From November 2015 to August 2018, data were collected from 3224 patients with ACS in 30 coronary care centers covering 11 governorates across Egypt, with focus premature ACS.

Results: The vast majority were males $(74 \%)$ and the most prevalent age group was (56-65 years) representing $37 \%$ of whole study population. Among female patients, $92 \%$ were post-menopausal. The prevalence of premature ACS was $51 \%$. Forty five percent of total males and $69.6 \%$ of total females with ACS had premature presentation $(\mathrm{P}<0.001)$. Abdominal obesity was the most prevalent risk factor $(66 \%)$. Nearly half of the entire study patients were current smokers (48\%). We showed a high prevalence of documented dyslipidemia $(48 \%)$ as well. Early invasive management strategy was employed in $65 \%$ of patients with no significant gender disparity noticed. Vascular access for coronary angiography was most commonly femoral ( $80 \%$ of time). Emergent percutaneous coronary intervention (PCI) was attempted in 53\% of patients. Thrombolytic therapy (using

\section{Introduction}

Cardiovascular disease (CVD) is one of the leading causes of mortality worldwide. In 2017, according to the Global Burden of Diseases study, there were 26.6 million deaths and 706 million disability-adjusted life-years (DALYs) of non-communicable disease. Importantly, ischemic heart disease (IHD) was the most attributable cause, resulting in 8.38 million deaths and 162 million DALYs. ${ }^{1}$ Although CVD mortality has been decreasing in the developed countries along the last decade, it is still on the rise in the developing countries. The fact that about $80 \%$ of the CVD burden is clustered within developing countries is alarming and calls for more investigation of the current status of risk factors' distribution and treatment strategies implemented to mitigate this risk. ${ }^{2,3}$

In 2011, the United Nations High Level Meeting set global target to reduce the risk of premature death [defined by the World Health Organization (WHO) as occurring from ages 30 to 70 years] with a $25 \%$ reduction in the probability of premature death attributable to CVD by the year 2025 ( 25 by 25 target). ${ }^{4}$ However, by 2020 the IHD mortality in the Eastern Mediterranean region (EMR) has a projecting increase of $146 \%$ for women and $174 \%$ for men, $\square^{5}$ which is a very worrisome for a region that is showing a rapid change in the CVD pattern due to the high prevalence of smoking (including water pipe), obesity, shifting from traditional eastern food to high calorie processed food and lack of physical activity. 6,7 Therefore, and for the aforementioned 2025 goal, we should take this demographic shift in lifestyle seriously.

Another issue that has been raised in the recent decade is the gender inequality for acute coronary syndromes (ACS) care, with
Correspondence: Ahmed Bendary, Department of Cardiology, Benha University, Benha, code: 13511, Egypt.

Tel.: +20.01220778216.

E-mail: ahmed.bendari@fmed.bu.edu.eg d dr_a_bendary@hotmail.com.

Key words: Egypt; Acute coronary syndrome; Risk factors.

Acknowledgements: We acknowledge the support of the Egyptian Association of Vascular Biology and Atherosclerosis (EAVA).

Contributions: AR conceived and designed the study, secured funding, interpreted data and critically re-vised the manuscript. MA, MS, HR, AE, WA, TM, MH, EF, HK, MW, AE, SS, GK, MS, MM, AA, OS, SR, YA, MS, NF, HE, HHA, SE, MB, AS, MY, MA, AG, YB, TM, $\mathrm{MZ}, \mathrm{AB}$ and $\mathrm{KR}$ undertook patient enrolment, data collection and revision of the manuscript. $\mathrm{MB}$ and $\mathrm{AB}$ analyzed data, RS, $\mathrm{BA}$, $A B$ wrote the manuscript. All authors have read and approved the final manuscript.

Conflict of interest: The authors declare no potential conflict of interest.

Funding: The study was funded by a grant from AstraZenica Egypt. The sponsors of the study had no role in data collection, analysis, interpretation, writing the report or the decision to submit it for publication.

Ethics approval and consent to participate: The study was approved by the ethics committee of the Egyp-tian Association of Vascular Biology and Atherosclerosis (EAVA) [http://cardio-risk.org/]. Participants re-ceived detailed information about the study, and their data were obtained only after signing an informed consent.

Received for publication: 23 February 2020. Revision received: 11 January 2021.

Accepted for publication: 26 January 2021.

This work is licensed under a Creative Commons Attribution NonCommercial 4.0 License (CC BY-NC 4.0).

(C) Copyright: the Author(s),2020

Licensee PAGEPress, Italy

Journal of Public Health in Africa 2020; 11:1368 doi:10.4081/jphia.2020.1368

some studies for instance reporting that women with ACS are less likely to undergo coronary angiography comparing to men $^{8-10}$ whereas others showed no difference. ${ }^{11,12}$

Egypt is the most populous country in the EMR region, however, there is a lack of data representing the risk factors' pattern of patients with ACS. Egypt Cardiorisk proj- 
ect is a multicenter cross-sectional study held by the Egyptian Association of Vascular Biology and Atherosclerosis (EAVA) to identify the baseline risk factors and characteristics of Egyptian patients with ACS. Phase I and II have reported a high prevalence of obesity, smoking and premature ACS. ${ }^{13}$ The objective of this final phase is to take wider look on the risk profile of ACS Egyptian patients with a larger population sample and more specific consideration to gender differences and patients with premature ACS.

\section{Materials and Methods}

\section{Ethical consideration}

The study was approved by the ethics committee of the Egyptian Association of Vascular Biology and Atherosclerosis (EAVA) [http://cardio-risk.org/] with approval number 3/2015. Participants received detailed information about the study, and their data were obtained only after signing an informed consent. Data protection of the participants were according to the Helsinki Declaration of 1975, as revised in 2013.

CardioRisk is a multi-centric, nationwide, observational, cross-sectional study assessing the risk factors, diagnostic procedures, and management approaches of ACS in Egypt. Data were collected from 30 coronary care centers in 11 governorates across Egypt to ensure proper representation of the different patient characteristics and variations in the management approaches between the centers.

This report presents a combined final analysis of the data collected in the three phases of the study (Phase I: November 2015 to January 2016; Phase II: February 2016 to August 2017; Phase III: September 2017 to August 2018). Results of the combined analysis of phase I and II were previously published. ${ }^{13}$

We included participants who were 18 years or older and were diagnosed with ST segment elevation myocardial infarction (STEMI), non-ST segment elevation myocardial infarction (NSTEMI), or unstable angina (UA). A diagnosis of ACS was made when two of the following criteria were met: 1) Electrocardiographic changes suggestive of acute ischemic changes, 2) compatible presenting symptoms, and 3) elevated Troponin I, and/or elevated CKMB (reported qualitatively according to each local center standardized laboratory method and cutoff level). Patients had to meet the criterion number 3 to be diagnosed as having STEMI/NSTEMI in the ACS spectrum. Patients diagnosed as having
ACS but presenting with manifestations other than chest pain and/or with nonobstructive CAD on subsequent coronary angiography were doubled-checked by 2 independent blinded experienced cardiologists regarding their presenting symptoms and ECG changes to ensure that they fulfill the criteria of ACS diagnosis.

Patients recruitment into the study was done all through the week or on fixed days for each center to minimize the selection bias. We did not impose any changes to the management strategies followed by each center, and the choice of the appropriate interventions and medications was totally left to participating cardiologists' judgement. However, assessment of medications was carried out at 2 time points; on admission (chronic medications) and at discharge. Medications assessed included: antiplatelets, statins, anti-ischemic, and anti-failure drugs. Early invasive strategy for management was defined as coronary angiography that is followed by potential intervention within the $1^{\text {st }} 24$ hours of presentation. Of note, for patients undergoing coronary angiography as part of their management plan, obstructive CAD was defined as $\geq 50 \%$ diameter stenosis. Participating investigators entered patients' data to an online case report form (CRF), with a unique username and password assigned to each investigator. Data were regularly checked and validated.

All included participants had a 12-lead electrocardiography (ECG), which was interpreted by a cardiologist. Plasma concentrations of troponins and CK-MB were also measured to determine the diagnosis. Other data collected included socio-demographics, anthropometric measures, risk factors, plasma levels of glycated hemoglobin (HbA1c), blood glucose, and lipid profile, previous and in-hospital cardiac interventions and medications.

Dyslipidemia was defined as having a history of lipid-lowering therapy or lowdensity lipoprotein (LDL) cholesterol $>70$ $\mathrm{mg} / \mathrm{dl}(>1.81 \mathrm{mmol} / \mathrm{l}) .{ }^{14}$ Hypertension was defined as having a history of hypertension or systolic/diastolic blood pressure 140/90 mmHg. ${ }^{15}$ Diabetes (type 1 or 2 ) were defined as a history of diabetes or fasting plasma glucose $>126 \mathrm{mg} / \mathrm{dl}$. Body weight and height were measured to the nearest 0.5 $\mathrm{kg}$ and $0.5 \mathrm{~cm}$, respectively. Weight was determined using a standard scale with the subjects barefoot and wearing light clothes. Height was measured using a wall-mounted stadiometer. Body mass index (BMI) was calculated as weight $(\mathrm{kg}) /$ height squared $\left(\mathrm{m}^{2}\right)$. Patients were considered overweight or obese if they had a BMI of 25-29.9 or $\geq 30 \mathrm{~kg} / \mathrm{m}^{2}$, respectively. Waist circumfer- ence was measured with a non-stretchable measuring tape at the level of the umbilicus. Central obesity was defined as a waist-tohip ratio $\geq 0.9 \mathrm{~cm}$ in males and $\geq 0.85 \mathrm{~cm}$ in females. ${ }^{16}$ Premature ACS was defined as the occurrence of ACS before the age of 55 years in males and 65 years in females. ${ }^{17,18}$ Ex-smoker status was defined as at least 6 months of complete abstinence. ${ }^{19}$

\section{Statistical analysis}

Data management and statistical analysis were done using SPSS vs.25. (IBM, Armonk, New York, United states). Numerical data was summarized as means and standard deviations or medians and ranges. Categorical data was summarized as numbers and percentages. Comparisons between males and females were done using independent $t$ test or Mann Whitney U test for normally and non-normally distributed numerical data respectively. Categorical data was compared according to gender and residence using Chi-square test. All $\mathrm{P}$ values were two sided. $\mathrm{P}$ values less than 0.05 were considered significant.

\section{Results}

\section{Socio-demographics, presentation and main clinical characteristics}

We included 3224 patients, of whom $25.7 \%$ were females. The prevalence of premature ACS (defined as males less than 55 years and females less than 65 years old) was $51 \%$. Forty five percent of total male and $69.6 \%$ of total females with ACS had premature presentation $(\mathrm{P}<0.001)$. Most participants came from urban residences $(48.4 \%)$ with no statistical difference between males and females. Women were significantly less educated than men, with $48.7 \%$ versus $21 \%$ receiving no or only primary school education. Fifty two percent of males presented with STEMI compared to only $36 \%$ of female patients $(\mathrm{P}<0.001)$, while other forms of ACS (UA and NSTEMI) were significantly higher in females. Dyspnea (as an atypical presentation for ACS) was significantly more common in female patients $(66 \%$ in female versus $52 \%$ in males, $\mathrm{P}<0.001$ ) (Table 1). Interestingly, among patients who did not have chest pain as the presenting symptom, only 6 were subsequently found to have non-obstructive CAD on coronary angiography (with no significant gender-difference in this minor group, $\mathrm{P}=0.38$ ). Patients with premature ACS tended to suffer from STEMI more frequently than other patients $(49.8 \%$ versus $45.6 \%, \mathrm{P}=0.035$ ) (Table 2). 


\section{Atherosclerotic risk factors}

Abdominal obesity was the most prevalent risk factor in the total population $(66.3 \%)$, followed by Hypertension (56.2\%) which showed a statistically significant graded increased prevalence with increasing age $(29 \%, 48.40 \%, 64.60 \%$ and $68.70 \%$ in age groups $\leq 45,46-55,56-65$ and $>65$ years respectively, $\mathrm{P}<0.001$.) Hypertension, dyslipidemia, T1DM, T2DM, and obesity were more prevalent among women while smoking and abdominal obesity were more common among men (Figure 1). Rates of current smokers were significantly higher in younger age group $\leq 45$ years compared to older age group (>65 years) $\quad(66.30 \%$ versus $33.10 \%$, $\mathrm{P}<0.001)$. Patients with urban residence showed a higher prevalence of hypertension and dyslipidemia, while those from rural areas had a significantly higher prevalence of abdominal obesity (Table 3). Surprisingly, rates of documented dyslipidemia were similar when comparing those with premature ACS to others (49\% versus $47.4 \%, \mathrm{P}=0.449$ ), with no significant difference regarding level of low-density lipoprotein-cholesterol (LDL-C) as well (131.7 \pm 48.5 versus $130.2 \pm 45.2 \mathrm{mg} / \mathrm{dl}$, $\mathrm{P}=0.4$ ). However, those with premature ACS were significantly found to be current smokers $(49.6 \%$ versus $46.6 \%$ for others, $\mathrm{P}<0.001$ ) (Table 2).

BMI was significantly higher in females compared to males (it was well into the

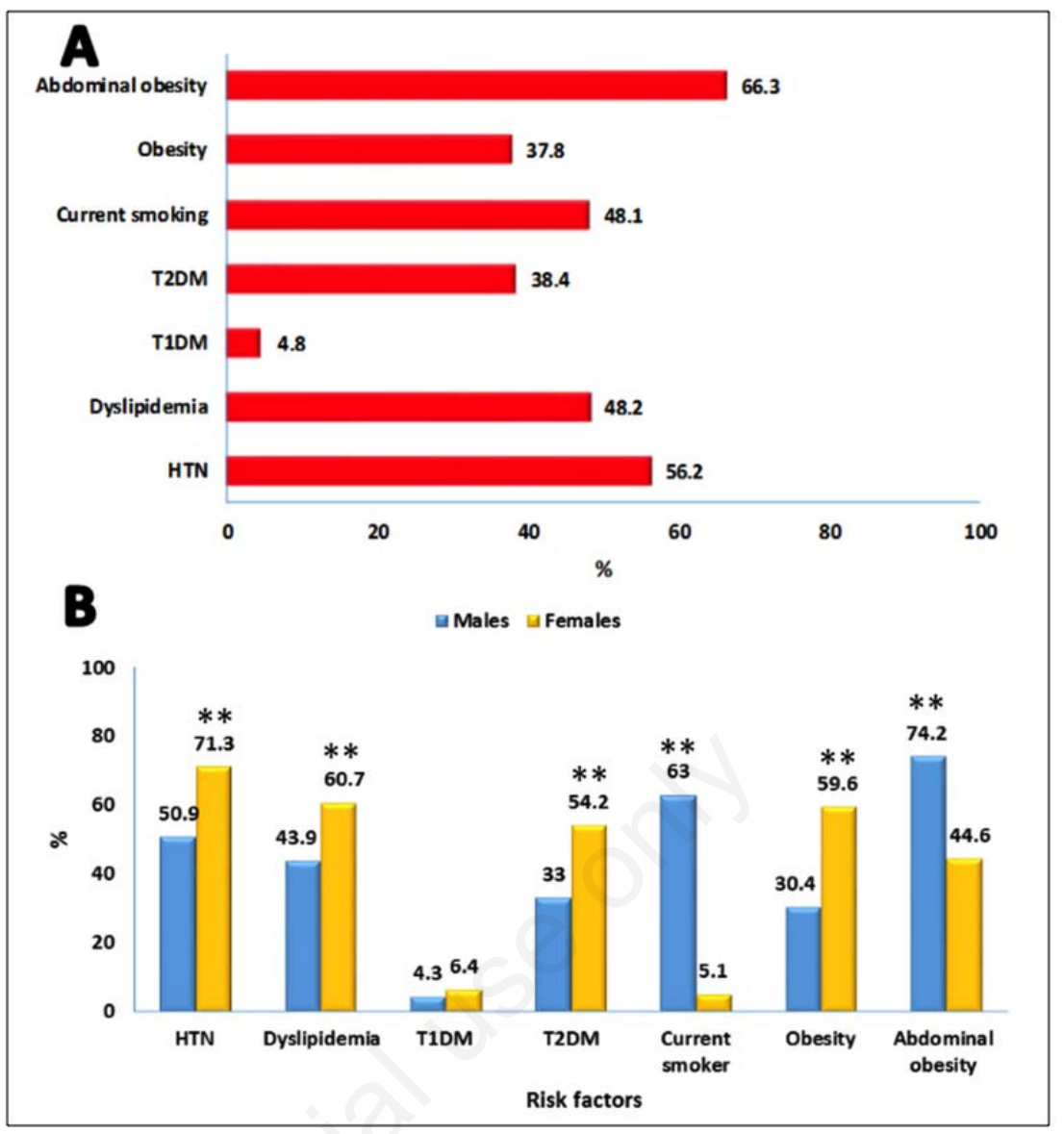

Figure 1. Distribution of traditional cardiovascular risk factors for the whole population (A) and according to gender (B). Percentages are from the total valid entries into the electronic CRFs. ${ }^{* *} \mathbf{P}$ value $<0.001$ versus the other group.

Table 1. Socio-demographics and main clinical characteristics at presentation.*

\begin{tabular}{|c|c|c|c|c|c|c|c|c|}
\hline \multirow[t]{2}{*}{ Characteristics } & & \multicolumn{2}{|c|}{ Total } & \multicolumn{2}{|c|}{ Males } & \multicolumn{2}{|c|}{ Females } & \multirow[t]{2}{*}{ P value } \\
\hline & & $\mathbf{N}$ & $\%$ & $\mathbf{N}$ & $\%$ & $\mathbf{N}$ & $\%$ & \\
\hline Age group & $\begin{array}{l}<35 \\
36 \text { to } 45 \\
46 \text { to } 55 \\
56 \text { to } 65 \\
66 \text { to } 75 \\
>75\end{array}$ & $\begin{array}{c}137 \\
308 \\
872 \\
1213 \\
549 \\
145\end{array}$ & $\begin{array}{c}4.2 \\
9.6 \\
27.0 \\
37.6 \\
17.0 \\
4.5\end{array}$ & $\begin{array}{l}110 \\
258 \\
705 \\
881 \\
358 \\
85\end{array}$ & $\begin{array}{c}4.60 \\
10.80 \\
29.40 \\
36.80 \\
14.90 \\
3.50\end{array}$ & $\begin{array}{c}27 \\
50 \\
167 \\
332 \\
191 \\
60\end{array}$ & $\begin{array}{c}3.30 \\
6.00 \\
20.20 \\
40.10 \\
23.10 \\
7.30\end{array}$ & $<0.001$ \\
\hline Residence & $\begin{array}{l}\text { Urban } \\
\text { Rural } \\
\text { Urban - Rural }\end{array}$ & $\begin{array}{l}1560 \\
990 \\
674\end{array}$ & $\begin{array}{l}48.4 \\
30.7 \\
20.9\end{array}$ & $\begin{array}{l}1188 \\
727 \\
482\end{array}$ & $\begin{array}{l}49.60 \\
30.30 \\
20.10\end{array}$ & $\begin{array}{l}372 \\
263 \\
192\end{array}$ & $\begin{array}{l}45.00 \\
31.80 \\
23.20\end{array}$ & 0.051 \\
\hline Level of education & $\begin{array}{l}\text { Primary } \\
\text { Secondary } \\
\text { High school/college } \\
\text { None }\end{array}$ & $\begin{array}{c}576 \\
1009 \\
1309 \\
330\end{array}$ & $\begin{array}{l}17.9 \\
31.3 \\
40.6 \\
10.2\end{array}$ & $\begin{array}{c}373 \\
764 \\
1130 \\
130\end{array}$ & $\begin{array}{c}15.60 \\
31.90 \\
47.10 \\
5.40\end{array}$ & $\begin{array}{l}203 \\
245 \\
179 \\
200\end{array}$ & $\begin{array}{l}24.50 \\
29.60 \\
21.60 \\
24.20\end{array}$ & $<0.001$ \\
\hline Initial diagnosis & $\begin{array}{l}\text { UA } \\
\text { NSTEMI } \\
\text { STEMI }\end{array}$ & $\begin{array}{c}735 \\
940 \\
1529\end{array}$ & $\begin{array}{l}22.9 \\
29.3 \\
47.7\end{array}$ & $\begin{array}{c}494 \\
660 \\
1234\end{array}$ & $\begin{array}{l}20.70 \\
27.60 \\
51.70\end{array}$ & $\begin{array}{l}241 \\
280 \\
295\end{array}$ & $\begin{array}{l}29.50 \\
34.30 \\
36.20\end{array}$ & $<0.001$ \\
\hline History of AMI & History of AMI & 539 & 17.0 & 425 & 18.00 & 114 & 14.00 & 0.01 \\
\hline Presenting symptoms & $\begin{array}{l}\text { Chest pain } \\
\text { Dyspnea } \\
\text { Cardiac arrest } \\
\text { Palpitation }\end{array}$ & $\begin{array}{c}3078 \\
1787 \\
94 \\
433\end{array}$ & $\begin{array}{c}96.1 \\
55.7 \\
2.9 \\
13.5\end{array}$ & $\begin{array}{c}2315 \\
1252 \\
74 \\
307\end{array}$ & $\begin{array}{c}96.80 \\
52.40 \\
3.10 \\
12.90\end{array}$ & $\begin{array}{c}763 \\
535 \\
20 \\
126\end{array}$ & $\begin{array}{c}93.80 \\
65.50 \\
2.50 \\
15.50\end{array}$ & $\begin{array}{c}<0.001 \\
<0.001 \\
0.349 \\
0.06\end{array}$ \\
\hline
\end{tabular}

*Percentages are calculated based on the total valid entries into the electronic CRFs. AMI=Acute myocardial infarction; NSTEMI=Non-ST segment elevation myocardial infarction; STEMI=ST-segment elevation myocardial infarction; $\mathrm{UA}=$ Unstable angina 
overweight range in males and into the obese range in females). Female patients had a worse lipid profile and metabolic parameter (including $\mathrm{HbA1C}$ ) compared to males. (Supplementary Table S1). Of note, patients with premature ACS has significantly higher BMI compared to other patients $\left(30 \pm 5\right.$ versus $29 \pm 5 \mathrm{~kg} / \mathrm{m}^{2}$, $\mathrm{P}<0.001$ ) (Table 2).

\section{In-hospital management and inter- ventions}

There was a very high adherence to evidence-based therapies for ACS during hospitalization, with more that $90 \%$ of patients receiving Aspirin, clopidogrel/ticagrelor and statins. More than $80 \%$ of patients received Beta-blockers and Angiotensin converting enzyme inhibitors/Angiotensin receptor blockers (ACEI/ARBs) as well. Low molecular weight heparin (LMWH) was the most commonly used parenteral anticoagulant (70.5\% of patients), followed by unfractionated heparin (UFH) $(26.9 \%)$ and then Fondaparinux (3.3\%). Interestingly, clopidogrel/ticagrelor and statins were prescribed more frequently for male patients compared to female ones (for clopidogrel/ticagrelor: $96.6 \%$ for males versus $93.9 \%$ for females, $\mathrm{P}=0.001$ and for statins: $94 \%$ for males versus $91 \%$ for females, $\mathrm{P}=0.003$ ) (Figure 2). This disparity was not observed when comparing patients with premature ACS to other patients, for which there were no statistically significant differences regarding rates of use of evidence-based medical therapies for ACS (including Aspirin [99.1\% versus 98.9, $\mathrm{P}=0.6]$, Clopidogrel/ticagrelor $[96.1 \%$ versus $95.7 \%, \mathrm{P}=0.5]$ and statins $[93.2 \%$ versus $93.3 \%, \mathrm{P}=0.8]$ ).

Regarding revascularization-related interventions, early invasive strategy for management with coronary angiography was performed in $64.8 \%$ of the total population, of whom PCI was attempted in 52.5\%. Eight percent of those who underwent early coronary angiography had normal epicar-

Table 2. Socio-demographics, clinico-biochemical parameters and interventions in premature ACS patients.*

\begin{tabular}{|c|c|c|c|c|c|c|c|c|}
\hline & \multirow{2}{*}{\multicolumn{2}{|c|}{ Total }} & \multicolumn{4}{|c|}{ Premature atherosclerosis } & \multirow[t]{3}{*}{ P value } \\
\hline & & & & & & & & \\
\hline & & $\mathbf{N}$ & $\%$ & $\mathbf{N}$ & $\%$ & $\mathrm{~N}$ & $\%$ & \\
\hline \multirow[t]{2}{*}{ Gender } & Males & 2397 & 74.3 & 1073 & 65.10 & 1324 & 84.10 & \multirow[t]{2}{*}{$<0.001$} \\
\hline & Females & 827 & 25.7 & 576 & 34.90 & 251 & 15.90 & \\
\hline \multirow[t]{3}{*}{ Residence } & Urban & 1560 & 48.4 & 807 & 48.90 & 753 & 47.80 & \multirow[t]{3}{*}{0.814} \\
\hline & Rural & 990 & 30.7 & 501 & 30.40 & 489 & 31.00 & \\
\hline & Urban - Rural & 674 & 20.9 & 341 & 20.70 & 333 & 21.10 & \\
\hline \multirow[t]{4}{*}{ Level of education } & Primary & 576 & 17.9 & 259 & 15.70 & 317 & 20.10 & \multirow[t]{4}{*}{$<0.001$} \\
\hline & Secondary & 1009 & 31.3 & 547 & 33.20 & 462 & 29.30 & \\
\hline & High school/college & 1309 & 40.6 & 710 & 43.10 & 599 & 38.00 & \\
\hline & None & 330 & 10.2 & 133 & 8.10 & 197 & 12.50 & \\
\hline \multirow[t]{3}{*}{ Initial diagnosis } & UA & 735 & 22.9 & 372 & 22.70 & 363 & 23.20 & \multirow[t]{3}{*}{0.035} \\
\hline & NSTEMI & 940 & 29.3 & 451 & 27.50 & 489 & 31.20 & \\
\hline & STEMI & 1529 & 47.7 & 815 & 49.80 & 714 & 45.60 & \\
\hline History of AMI & Yes & 539 & 17.0 & 251 & 15.40 & 288 & 18.60 & 0.018 \\
\hline \multirow[t]{4}{*}{ Presenting symptoms } & Chest pain & 3078 & 96.1 & 1570 & 96.10 & 1508 & 96.10 & 0.963 \\
\hline & Dyspnea & 1787 & 55.7 & 891 & 54.30 & 896 & 57.30 & 0.092 \\
\hline & Cardiac arrest & 94 & 2.9 & 49 & 3.00 & 45 & 2.90 & 0.824 \\
\hline & Palpitation & 433 & 13.5 & 227 & 13.90 & 206 & 13.20 & 0.552 \\
\hline \multirow[t]{6}{*}{ Risk factors } & HTN & 1811 & 56.2 & 803 & 48.70 & 1008 & 64.00 & $<0.001$ \\
\hline & Dyslipidemia & 1166 & 48.2 & 607 & 49.00 & 559 & 47.40 & 0.449 \\
\hline & TIDM & 156 & 4.8 & 97 & 5.90 & 59 & 3.70 & 0.005 \\
\hline & T2DM & 1238 & 38.4 & 581 & 35.20 & 657 & 41.70 & $<0.001$ \\
\hline & Current smoking & 1552 & 48.1 & 818 & 49.60 & 734 & 46.60 & $<0.001$ \\
\hline & Abdominal obesity & 1626 & 66.3 & 810 & 63.30 & 816 & 69.40 & 0.001 \\
\hline \multirow[t]{8}{*}{ Biochemical measures** } & BMI & 29 & 5 & 30 & 5 & 29 & 5 & $<0.001$ \\
\hline & Waist & 95.7 & 13.7 & 96 & 13.8 & 95.4 & 13.5 & 0.268 \\
\hline & Waist-hip ratio & 1.14 & 0.48 & 1.14 & 0.48 & 1.14 & 0.48 & 0.997 \\
\hline & LDL-C & 131 & 46.9 & 131.7 & 48.5 & 130.2 & 45.2 & 0.4 \\
\hline & HDL-C & 42.2 & 18.7 & 42.3 & 20.2 & 42.1 & 17 & 0.79 \\
\hline & $\mathrm{TC}$ & 194.6 & 55.1 & 197.2 & 57.9 & 191.9 & 51.9 & 0.007 \\
\hline & TGs (Median \& range) & 150 & $(0-1330)$ & \multicolumn{2}{|c|}{$152(0-1330)$} & \multicolumn{2}{|c|}{$145(0-729)$} & $<0.001$ \\
\hline & $\mathrm{HbAlC}$ & 6.69 & 1.78 & 6.72 & 1.93 & 6.65 & 1.62 & 0.304 \\
\hline \multirow[t]{9}{*}{ Therapeutic interventions } & Coronary angiography (Yes) & 2066 & 64.8 & 1075 & 66.20 & 991 & 63.40 & 0.109 \\
\hline & Vascular access: & & & & & & & \multirow{2}{*}{0.126} \\
\hline & $\begin{array}{l}\text { Radial } \\
\text { Femoral }\end{array}$ & $\begin{array}{c}404 \\
1662\end{array}$ & 19.6 & $\begin{array}{l}224 \\
851\end{array}$ & $\begin{array}{l}20.80 \\
79.20\end{array}$ & $\begin{array}{l}180 \\
811\end{array}$ & $\begin{array}{l}18.20 \\
81.80\end{array}$ & \\
\hline & Non-obstructive CAD on CA & $\begin{array}{l}1662 \\
161\end{array}$ & $\begin{array}{l}0.4^{2} \\
7.8\end{array}$ & $\begin{array}{l}0.1 \\
106\end{array}$ & $\begin{array}{c}19.20 \\
9.90\end{array}$ & $\begin{array}{c}811 \\
55\end{array}$ & $\begin{array}{c}01.00 \\
5.50\end{array}$ & $<0.001$ \\
\hline & PCI attempted? & 1590 & 52.5 & 831 & 54.00 & 759 & 50.90 & 0.082 \\
\hline & $\mathrm{CABG}$ & 170 & 5.3 & 68 & 4.20 & 102 & 6.50 & 0.003 \\
\hline & Temporary pacemaker & 60 & 1.9 & 22 & 1.30 & 38 & 2.40 & 0.025 \\
\hline & Permanent pacemaker & 15 & 0.5 & 4 & 0.20 & 11 & 0.70 & 0.058 \\
\hline & Thrombolysis & 763 & 23.9 & 437 & 26.70 & 326 & 20.80 & $<0.001$ \\
\hline
\end{tabular}

*Percentages are calculated based on the total valid entries into the electronic $\mathrm{CRFs}$. **Presented as mean $\pm \mathrm{SD}$. $\mathrm{AMI}=\mathrm{Acute}$ myocardial infarction; $\mathrm{BMI}=\mathrm{Body}$ mass index; $\mathrm{CA}=\mathrm{coronary}$ angiography; $\mathrm{CABG=Coronary}$ artery bypass graft; HDL-C=High density lipoprotein cholesterol; HTN=Hypertension; LDL-C=Low density lipoprotein cholesterol; NSTEMI=Non-ST segment elevation myo-cardial infarction; PCI=Percutaneous coronary intervention; SD=Standard Deviation; STEMI=ST segment elevation myocardial infarction; T1DM=Type-1 diabetes mellitus, T2DM=Type-2 diabetes mellitus; TG=Triglycerides; TC=total cholesterol UA=Unstable angina. 
dial coronary arteries. The vast majority of vascular accesses was through femoral artery $(80.4 \%$ of cases). Thrombolysis (using Streptokinase) was used in almost quarter of the total population (23.9\%). Urgent coronary artery bypass graft (CABG) was performed in $5.3 \%$ of patients. Only $1.9 \%$ of admitted patients were subjected to temporary pacemaker secondary to various degrees of ACS-associated bradyarrhythmias $(0.5 \%$ went to have a permanent pacemaker). Of note, rates of early invasive strategy were similar between males and females, with significantly higher male patients undergoing PCI. Female patients had a higher percentage of nonobstructive CAD on coronary angiography compared to their male counterparts. (Supplementary Table S2). There was no trend to treat patients with premature ACS more aggressively with an early invasive strategy compared to others $(66.2 \%$ versus $63.4 \%$ undergoing early coronary angiography in both groups respectively, $\mathrm{P}=0.1$ ). Moreover, rates of apparently normal epicardial coronary arteries in coronary angiography were significantly higher in those with a diagnosis of premature ACS compared to other population $(9.9 \%$ versus $5.5 \%$ respectively, $\mathrm{P}<0.001$ ) (Table 2 ).

\section{Discussion}

The Eastern Mediterranean (EMR) region, one of the six official WHO-designated geographical areas, comprises 22 countries and territories (Afghanistan, Bahrain, Djibouti, Egypt, Iran, Iraq, Jordan, Kuwait, Lebanon, Libya, Morocco, Oman, Pakistan, Palestine, Qatar, Saudi Arabia, Somalia, Sudan, Syria, Tunisia, United Arab Emirates (UAE), and Yemen), with a population of $\sim 583$ million people. $^{20}$ Gender difference has long been a cornerstone point in cardiovascular outcomes research, considering the fact that manifest atherosclerotic cardiovascular disease (ASCVD) is reported to have a delayed onset of about 10 years or more in women ${ }^{21}$ and that menopause is a leading risk factor in women due to the protective role of the circulating Estrogen. ${ }^{22}$ Despite this increased focus on the gender disparities in IHD, age and sex interaction is still underinvestigated.

The current study revealed a significantly higher prevalence of ACS in males compared to females among age groups less than 55 years, on the contrary it rises sharply in females in age groups $>55$ years. Estrogen has always been hypothetically thought to be the protective factor for premenopausal women. However, Cochran systematic reviews concluded that this might not be the case. ${ }^{23,24} \mathrm{We}$ also showed that the prevalence of the traditional cardiovascular risk factors (DM, HTN, Dyslipidemia and obesity) tended to be higher in women except smoking which was significantly higher in men. This fact, in and of itself, makes sense and points to a worse metabolic and cardiovascular risk pattern among Egyptian females. This might be considered a call for action to openly discuss the future ASCVD risk with female patients in a deeper manner, considering the disappointing data coming from the VIRGO study, ${ }^{25}$ which indicated that health care providers are $11 \%$ less likely to discuss the future ASCVD risk with young women compared to young men.

According to Global Registry of Acute Coronary Events (GRACE) registry and other reports, ${ }^{26,27}$ women with ACS tended to present with atypical symptoms such as nausea and vomiting rather than chest pain. Similarly, we showed that women presented with chest pain in rates lower than their male counterparts with higher prevalence of atypical symptoms as dyspnea. Interestingly, rates of early invasive strategy for treating patients with ACS were similar between males and females (65.1 versus 64.1, $\mathrm{P}=0.6$ ), despite the data pointing to the underuse of early invasive and more aggressive managements among females. ${ }^{28,29}$ This is considered a good step forward which reflects the impact of Egyptian national awareness campaigns. However, we revealed that female patients were significantly less prescribed clopidogrel/ticagrelor and also tended to have lesser prescription

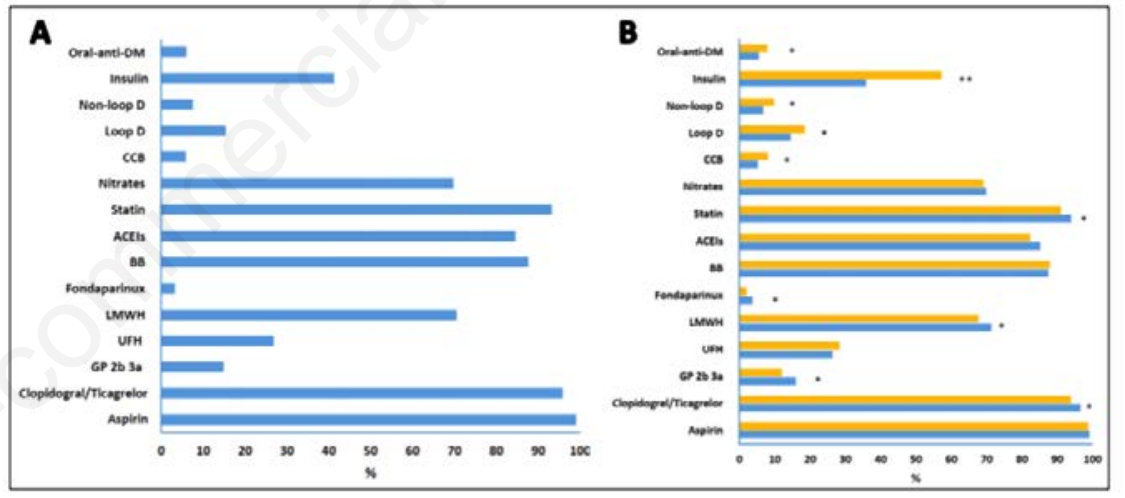

Figure 2. Commonly prescribed in-hospital medications for (A) the total population and (B) according to gender. Percentages are from the total valid entries into the electronic CRFs. ${ }^{*} P$ value $<0.05$ and ${ }^{* *} P$ value $<0.001$ versus the other group.

Table 3. Traditional cardiovascular risk factors' distribution according to residence.*

\begin{tabular}{|c|c|c|c|c|c|c|c|c|}
\hline & \multicolumn{2}{|c|}{ Urban } & \multicolumn{2}{|c|}{ Rural } & \multicolumn{2}{|c|}{ Urban-Rural } & \multirow[t]{2}{*}{ P value } \\
\hline & & $\mathbf{N}$ & $\%$ & $\mathbf{N}$ & $\%$ & $\mathbf{N}$ & $\%$ & \\
\hline HTN & Yes & 870 & 55.80 & 493 & 49.80 & 448 & 66.50 & $<0.001$ \\
\hline Dyslipidemia & Yes & 564 & 48.20 & 231 & 33.40 & 371 & 66.40 & $<0.001$ \\
\hline T1DM & Yes & 74 & 4.70 & 61 & 6.20 & 21 & 3.10 & 0.017 \\
\hline T2DM & Yes & 622 & 39.90 & 380 & 38.40 & 236 & 35.00 & 0.096 \\
\hline Smoking & $\begin{array}{l}\text { Yes } \\
\text { Ex-Smoker }\end{array}$ & $\begin{array}{l}759 \\
186\end{array}$ & $\begin{array}{l}48.70 \\
11.90\end{array}$ & $\begin{array}{l}484 \\
111\end{array}$ & $\begin{array}{l}48.90 \\
11.20\end{array}$ & $\begin{array}{l}309 \\
82\end{array}$ & $\begin{array}{l}45.80 \\
12.20\end{array}$ & 0.716 \\
\hline BMI & $\begin{array}{l}\text { Normal } \\
\text { Overweight } \\
\text { Obesity }\end{array}$ & $\begin{array}{l}170 \\
730 \\
507 \\
\end{array}$ & $\begin{array}{l}12.10 \\
51.90 \\
36.00 \\
\end{array}$ & $\begin{array}{l}162 \\
427 \\
356 \\
\end{array}$ & $\begin{array}{l}17.10 \\
45.20 \\
37.70 \\
\end{array}$ & $\begin{array}{c}46 \\
223 \\
207 \\
\end{array}$ & $\begin{array}{c}9.70 \\
46.80 \\
43.50\end{array}$ & $<0.001$ \\
\hline Abdominal obesity & Yes & 859 & 70.30 & 605 & 75.80 & 162 & 37.30 & $<0.001$ \\
\hline
\end{tabular}

* Percentages are calculated based on the total valid entries into the electronic CRFs. BMI=Body mass index; HTN=Hypertension; T1DM=Type-I diabetes mellitus; T2DM=Type-II diabetes mellitus 
of LMWH relative to males. This could be explained by the ubiquitous belief of the feminine higher risk of bleeding with antithrombotics. ${ }^{30}$

Premature ACS is defined as the ACS in men $\leq 55$ years or women $\leq 65$ years. ${ }^{17,18}$ The middle east has the youngest median age of first MI (51 years) compared to North America (59 years) and Western Europe (63 years), according to The Effect of Potentially Modifiable Risk Factors Associated with Myocardial Infarction (INTERHEART) (case-control) study. $^{2}$ Consistent with GRACE, Gulf RACE, ${ }^{31}$ Gulf RACE- $2^{31}$ and INTERHEART studies; smoking was more prevalent in younger age versus older age with ACS $(66.3 \%$ in age group $>45$ versus $33.1 \%$ in age group $>75$ ). The current study showed a lower prevalence of T2DM and HTN in patients with premature presentation compared to others, and this is in accordance with the GRACE, ${ }^{18}$ GULF RACE I and II, ${ }^{32}$ but on the contrary to the results of the INTERHEART study which showed a higher prevalence in patients with premature presentation. $^{2}$ Our data point to no significant differences in plasma lipid parameters across different age groups, whereas the INTERHEART $^{2}$ and GRACE registry ${ }^{18}$ have shown higher levels associated with younger age groups, in contrast to the GULF RACE I and II ${ }^{31,32}$ that have shown lower levels. Our study's observations support that the EMR individuals with premature ACS have higher prevalence of obesity and smoking compared with older age groups and lower prevalence of the traditional risk factors (DM, HTN and dyslipidemia). Future studies are underway to investigate the risk profile of EMR with premature CAD particularly lifestyle factors, diet and physical activity and most importantly the family history. ${ }^{33}$

Obesity prevalence in the EMR comes in the $3^{\text {rd }}$ place of the global high rates' ranking (at $23.6 \%$ for women and $14.6 \%$ for men). According to the WHO, it turns out that about $50 \%$ the EMR women are overweight with highest rates in Bahrein and Qatar followed by Egypt. ${ }^{20}$ Moreover, about $50-80 \%$ of adults in the EMR are overweight with higher prevalence in females which is only exceeded with USA. ${ }^{34}$ Not surprisingly, abdominal obesity was the most prevalent traditional risk factor at $66.3 \%$ among our patients, the rates were similar between the urban and rural areas and tends to be higher in men. Notably, BMI has shown significant steady increments across the region particularly in women with $28 \mathrm{~kg} / \mathrm{m}^{2}$ between 1980 and $2008 .^{35,36}$ We speculate that this is mostly due to the urbanization and modernization of the EMR area in the last decades, with dramatic shifting from the eastern diet rich in whole cereals, olive oil, fruit, fish, and vegetables to the western diet style with high fats and cholesterol. ${ }^{37}$

Smoking is one of the most prevalent traditional risk factors in our study with figures reaching up to $48 \%$ of the entire population as current smokers and $11.8 \%$ as exsmokers. Highest rates were found among age group $>45$ years with dramatically higher rates in men compared to women (63\% versus $5 \%$ ), and this could be understood through the conservative cultural nature of the area. In 2015, the WHO reported that the EMR smoking prevalence was $25.4 \%$, this is higher than the global prevalence $(22.7 \%)$, but lower than in Europe $(27.3 \%)$ and the western Pacific regions $(25.8 \%) .{ }^{38}$ These alarming rates urge for adopting novel methods to control smoking in the region. One of the effective approaches is the restrictive increases in taxes on cigarette packs to about 1.37 \$, however it's still below the average and considered the lowest average after southeastern countries. ${ }^{39}$

The Egyptian national hypertension project (of about 7000 participants) had reported that HTN is at $26 \%$ prevalence in Egypt and is a leading cause of many cardiovascular diseases. This was close to rates reported for Tunisia (a country with similar socio-demographics to Egypt). ${ }^{40,41}$ In our study, HTN was found to be the $2^{\text {nd }}$ most common risk factor (at $56 \%$ prevalence among Egyptians with ACS), with positive association with age and higher prevalence in females. Importantly, our study revealed a higher prevalence of HTN in people with higher education and urban residency, which can be explained with evolving stressful life associated with higher social status together with the medical cultural awareness that could definitely lead to an earlier diagnosis.

The global prevalence of diabetes mellitus in 2014 was $9 \%{ }^{42}$ The International Diabetes Foundation (IDF) reported the highest prevalence of diabetes to be found in the MENA region at $12.5 \%$ compared to $6 \%$ in Europe and 8.6\% in Southeast Asia. ${ }^{43}$ Moreover, they are expecting these numbers to be doubled by 2040 due to increasing rates of impaired glucose tolerance. ${ }^{35}$ The IDF also reported that about $40 \%$ of the MENA region population with genuine DM are undiagnosed which forms a huge CVD burden since DM is one of the most prevalent risk factors for future ASCVD. In our study T1DM and T2DM were reported to affect $4.8 \%$ and $38.4 \%$ of Egyptians with ACS with higher prevalence in females, urban areas and high educational classes.
The fact that the major traditional cardiovascular risk factor among our patient population is abdominal obesity is worrisome as abdominal adiposity is closely linked to the development of insulin resistance, ${ }^{44}$ a well-known harbinger of DM.

Dyslipidemia rates varies across the literature due to different definitions that are changing overtime. ${ }^{35}$ In the current report, the prevalence of documented dyslipidemia was reported to be lingering around $48 \%$, exceeding the highest rate in gulf countries (Bahrein at 45\%). ${ }^{32}$ Importantly, we showed a higher prevalence of dyslipidemia among females versus males and in urban versus rural residents $(48 \%$ versus $33.4 \%$, $\mathrm{P}$ $<0.001$ ) which also can be understood through the diet shifting and urbanization. Our finding that females were less likely to receive statins compared to their male counterparts is consistent with some international data, ${ }^{45}$ and could be partly explained by the fact that statin-related side effects are anecdotally thought to be more common in females, but the main driver for such a gender-disparity remains elusive.

The current study is not without limitations. First, the observational nature of the study makes it to fall short of providing causal inferences between any cardiovascular risk factor and the occurrence of ACS. Second, the lack of reporting in-hospital outcomes is mainly due to the 2 reasons; (1) we aimed primarily through the current report to figure out the national picture of cardiovascular risk factors among a very high-risk group and (2) absence of a wellestablished in-hospital record systems for reporting outcomes. Lastly, we did not report some biochemical markers such as cardiac Troponins and NT-proBNP due to factors related to lack of standardization of Troponin assays among different laboratories in various coronary care units, in addition to the costs associated with ordering some of these tests (NT-proBNP).

\section{Conclusions}

Among Egyptian patients with ACS, premature presentation is common $(51 \%$ of cases, with significant higher male preponderance), with abdominal obesity is the most prevalent risk factor. Most traditional risk factors (apart from smoking) were more prevalent in women than men. There was a very good adherence to evidencebased medical therapies for hospitalized ACS patients (with modest gender disparity). Females had similar chances for an early invasive management strategy with coronary angiography compared to their male counterparts. Our data may help 
founding age- and gender-specific preventive and management developmental strategies to close the gap between international guidelines' recommendations and the reality in Egypt.

\section{References}

1. Stanaway JD, Afshin A, Gakidou E, et al. Global, regional, and national comparative risk assessment of 84 behavioural, environmental and occupational, and metabolic risks or clusters of risks for 195 countries and territories, 1990 2017: a systematic analysis for the Global Burden of Disease Study 2017. The Lancet 2018;392:1923-94.

2. Yusuf S, Hawken S, Ônpuu S, et al. Effect of potentially modifiable risk factors associated with myocardial infarction in 52 countries (the INTERHEART study): case-control study. Lancet 2004;364:937-52.

3. Primatesta, P. Guidelines and risk factor management. Heart 2005;91:417.

4. Roth GA, Huffman MD, Moran AE, et al. Global and regional patterns in cardiovascular mortality from 1990 to 2013. Circulation 2015;132:1667-78.

5. Yusuf S, Reddy S, Ôunpuu S, Anand S. Global burden of cardiovascular diseases: part I: general considerations, the epidemiologic transition, risk factors, and impact of urbanization. Circulation 2001;104: 2746-53.

6. Popkin BM, Adair LS, Ng SW. Global nutrition transition and the pandemic of obesity in developing countries. Nutr Rev 2012;70:3-21.

7. Maziak W. The global epidemic of waterpipe smoking. Add Behav 2011;36:1-5.

8. Gottlieb S, Harpaz D, Shotan A, et al. Sex differences in management and outcome after acute myocardial infarction in the 1990s: a prospective observational community-based study. Circulation 2000;102:2484-90.

9. Bearden D, Allman R, McDonald R, et al. Age, race, and gender variation in the utilization of coronary artery bypass surgery and angioplasty in SHEP. J Am Geriatr Soc 1994;42:1143-9.

10. Shehab A, Al-Dabbagh B, AlHabib KF, et al. Gender disparities in the presentation, management and outcomes of acute coronary syndrome patients: data from the 2nd Gulf Registry of Acute Coronary Events (Gulf RACE-2). PloS One 2013;8:55508

11. Perers E, Caidahl K, Herlitz J, et al. Treatment and short-term outcome in women and men with acute coronary syndromes. Int J Cardiol 2005;103:1207.

12. Alfredsson J, Stenestrand U, Wallentin L, Swahn E. Gender differences in management and outcome in non-ST-elevation acute coronary syndrome. Heart 2007;93:1357-62.

13. Reda A, Ashraf M, Soliman M, et al. The pattern of risk-factor profile in Egyptian patients with acute coronary syndrome: phase II of the Egyptian cross-sectional CardioRisk project. Cardiovasc J Afr 2019;30:87-94.

14. Catapano AL, Graham I, De Backer G, et al. ESC/EAS guidelines for the management of dyslipidaemias: the task force for the management of dyslipidaemias of the European Society of Cardiology (ESC) and European Atherosclerosis Society (EAS) developed with the special contribution of the European Association for Cardiovascular Prevention \& Rehabilitation (EACPR). Atherosclerosis 2016;253:281-344.

15. Williams B, Mancia G, Spiering W, et al. ESC/ESH Guidelines for the management of arterial hypertension. Eur Heart J 2018;39:3021-104.

16. Waist Circumference and Waist-Hip Ratio Report of a WHO Expert Consultation (2008). Available at: https://apps.who.int/iris/bitstream/1066 5/44583/1/9789241501491 eng.pdf. Accessed January 2020.

17. Lloyd-Jones DM, Nam BH, D'Agostino SR, et al. Parental cardiovascular disease as a risk factor for cardiovascular disease in middle-aged adults: a prospective study of parents and offspring. JAMA 2004;291:220411 .

18. Avezum A, Makdisse M, Spencer F, et al. Impact of age on management and outcome of acute coronary syndrome: observations from the Global Registry of Acute Coronary Events (G Coronary Heart Disease in the Middle East). Am Heart J 2005;149:67-73.

19. Dehmer GJ, Badhwar V, Bermudez AE, et al. AHA/ACC Key Data Elements and Definitions for Coronary Revascularization: A Report of the American College of Cardiology/ American Heart Association Task Force on Clinical Data Standards (Writing Committee to Develop Clinical Data Standards for Coronary Revascularization). Circulation 2020;13:e000059.

20. World Health Organization (2019). Available at: http:/www.emro.who.int/ entity/about-us/index.html. Accessed June 2019.
21. International

Epidemiological Association Guidelines (2019). Available at: https://ieaweb.org/. Accessed June 2019.

22. Chakrabarti S, Morton JS, Davidge ST. Mechanisms of estrogen effects on the endothelium: an overview. Canad J Cardiol 2014;30:705-12.

23. Mendelsohn ME, Karas RH. The protective effects of estrogen on the cardiovascular system. New Engl J Med 1999;23:1801-11.

24. Marjoribanks J, Farquhar C, Robert H, Lethaby A. Long term hormone therapy for perimenopausal and postmenopausal women. Cochrane Datab Syst Rev 2012;7.

25. Leifheit-Limson EC, D'Onofrio G, Daneshvar M, et al. Sex differences in cardiac risk factors, perceived risk, and health care provider discussion of risk and risk modification among young patients with acute myocardial infarction: the VIRGO study. J Am Coll Cardiol 2015;66:1949-57.

26. Dey S, Flather MD, Devlin G, et al. Sex-related differences in the presentation, treatment and outcomes among patients with acute coronary syndromes: the Global Registry of Acute Coronary Events. Heart 2009;95:20-6.

27. Pagidipati NJ, Peterson ED. Acute coronary syndromes in women and men. Nat Rev Cardiol 2016;13:471

28. Jneid H, Fonarow GC, Cannon CP, et al. Get With the Guidelines Steering C, Investigators. Sex differences in medical care and early death after acute myocardial infarction. Circulation 2008;118:2803-10.

29. Hess CN, McCoy LA, Duggirala HJ, et al. Sex $\square$ based differences in outcomes after percutaneous coronary intervention for acute myocardial infarction: a report from TRANSLATE-ACS. J Am Heart Assoc 2014;3:000523.

30. Chen AY. Baseline risk of major bleeding in non-ST segment elevation myocardial infarction: the CRUSADE bleeding score. Circulation 2009;119:2168-94.

31. Zubaid M, Rashed WA, Al-Khaja N, et al. Clinical presentation and outcomes of acute coronary syndromes in the gulf registry of acute coronary events (Gulf RACE). Saudi Med J 2008;29:251-5.

32. AlHabib KF, Sulaiman K, Al-Motarreb A, et al. Baseline characteristics, management practices, and long-term outcomes of Middle Eastern patients in the Second Gulf Registry of Acute Coronary Events (Gulf RACE-2). Ann Saudi Med 2012;32:9-18.

33. Dugani SB, Murad W, Damilig K, et al. 
Premature Myocardial Infarction in the Middle East and North Africa: Rationale for the Gulf PREVENT Study. Angiology 2019:0003319719849737.

34. Musaiger AO. Overweight and obesity in eastern mediterranean region: prevalence and possible causes. J Obesity 2011.

35. Traina MI, Almahmeed W, Edris A, Tuzcu EM. Coronary heart disease in the Middle East and North Africa: current status and future goals. Curr Atheroscler Rep 2017;19:24.

36. Finucane MM, Stevens GA, Cowan MJ, et al. systematic analysis of health examination surveys and epidemiological studies with 960 country-years and 9.1 million participants. Lancet 1980;377:557-67.

37. Aljefree N, Ahmed F. Association between dietary pattern and risk of cardiovascular disease among adults in the
Middle East and North Africa region: a systematic review. Food Nutr Res 2015;59:27486.

38. World Health Organization (2016). World Health Statistics 2016 data visualizations dashboard: prevalence of tobacco smoking. Available at: http://apps.who.int/gho/data/node.sdg.3 -a-viz?lang=en. Accessed June 2019

39. World Health Organization (2012). Global progress report on implementation of the WHO framework convention on tobacco control. Available at: https://apps.who.int/iris/handle/10665/7 9170. Accessed June 2019.

40. Ibrahim MM, Appel LJ, Rizk HH, et al. Cardiovascular risk factors in normotensive and hypertensive Egyptians. J Hypertens 2001;19:1933-40.

41. Romdhane HB, Ali SB, Skhiri H, et al. Hypertension among Tunisian adults: results of the TAHINA project. Hypertens Res 2012;35:341.
42. World Health Organization (2014). Global status report on noncommunicable diseases. Available at https://www.who.int/nmh/publications/ncd-status-report-2014/en/. Accessed June 2019

43. Whiting DR, Guariguata L, Weil C, Shaw J. IDF diabetes atlas: global estimates of the prevalence of diabetes for 2011 and 2030. Diabet Res Clin Pract 2011;94:311-21

44. Weyer C, Foley JE, Bogardus C, et al. Enlarged subcutaneous abdominal adipocyte size, but not obesity itself, predicts type II diabetes independent of insulin resistance. Diabetologia 2000;43:1498-506.

45. Huabing Z, Plutzky J, Shubina M, Turchin A. Drivers of the sex disparity in statin therapy in patients with coronary artery disease: a cohort study. PLoS 2016;e0155228. 